\title{
ARRANJO ESPACIAL, DENSIDADE E ÉPOCA DE SEMEADURA NO ACÚMULO DE MATÉRIA SECA E NUTRIENTES DE TRÊS ADUBOS VERDES ${ }^{1}$
}

\author{
Juliana Domingues Lima², Ronaldo Kazuo Sakai ${ }^{3}$, Michel Aldrighi ${ }^{4}$, Mauro Sakai ${ }^{5}$
}

\section{ABSTRACT \\ SPATIAL ARRANGEMENT, SOWING DENSITY \\ AND DATE ON DRY MATTER AND NUTRIENT \\ ACCUMULATION OF THREE GREEN MANURES}

The main objective of the study was to evaluate the effect of sowing densities, spatial arrangements and sowing dates in the accumulation of dry matter and nutrients in Crotalaria juncea, Mucuna deeringiana, and Cajanus cajan, in Pariquera-Açu, Vale do Ribeira, São Paulo State, Brazil. Three experiments were carried out: 1) sowing density x green manures, 2) spatial arrangement $\mathrm{x}$ green manures, and 3 ) sowing date $\mathrm{x}$ green manures. The experimental design was randomized complete blocks, with four replications, with the first experiments in a factorial scheme and the third in a split-plot arrangement. When plants reached $50 \%$ of flowering, the accumulation of dry matter, macronutrients, micronutrients, and organic carbon in the shoot were determined. Higher sowing densities reduce the accumulation of dry matter, $\mathrm{B}$, and $\mathrm{Zn}$, in Crotalaria juncea and Mucuna deeringiana; the accumulation of $\mathrm{P}$ in Mucuna deeringiana and Cajanus cajan; and the accumulation of $\mathrm{N}, \mathrm{S}$, and $\mathrm{Cu}$ in all green manures. The spatial arrangement does not affect the accumulation of dry matter and nutrients. Based on the accumulation of dry matter and nutrients, Crotalaria juncea is the most efficient species for use as green manure, when sown in November. Crotalaria juncea, Mucuna deeringiana, and Cajanus cajan show low performance in the accumulation of dry matter and nutrients, when sown at later dates.

KEY-WORDS: Crotalaria juncea; Mucuna deeringiana; Cajanus cajan; phytomass.

\section{INTRODUÇÃO}

A preocupação com o avanço do processo degradativo instalado em grande parte dos solos brasileiros e com a prevenção da degradação de novas

\section{RESUMO}

Objetivou-se avaliar o efeito de densidades de semeadura, arranjos espaciais e épocas de semeadura no acúmulo de matéria seca e nutrientes de Crotalaria juncea, Mucuna deeringiana e Cajanus cajan, em Pariquera-Açu, Vale do Ribeira (SP). Três experimentos foram conduzidos: 1) densidade de semeadura $x$ adubos verdes, 2) arranjo espacial $x$ adubos verdes e 3 ) época de semeadura $x$ adubos verdes. O delineamento experimental adotado foi o de blocos casualizados, com quatro repetições, sendo os primeiros experimentos arranjados em esquema fatorial e o terceiro em parcela subdividida. Quando as plantas atingiram $50 \%$ de floração, foram determinados o acúmulo de matéria seca, macronutrientes, micronutrientes e carbono orgânico na parte aérea. Maiores densidades de semeadura reduzem o acúmulo de matéria seca, B e Zn em Crotalaria juncea e Mucuna deeringiana; o acúmulo de P em Mucuna deeringiana e Cajanus cajan; e o acúmulo de N, S e Cu em todos os adubos verdes. $\mathrm{O}$ arranjo espacial não afeta $\mathrm{o}$ acúmulo de matéria seca e nutrientes. Com base no acúmulo de matéria seca e de nutrientes, Crotalaria juncea é a espécie mais eficiente para uso como adubo verde, quando semeada em novembro. Crotalaria juncea, Mucuna deeringiana e Cajanus cajan apresentam baixo desempenho na acumulação de matéria seca e nutrientes, quando semeadas em épocas tardias.

PALAVRAS-CHAVE: Crotalaria juncea; Mucuna deeringiana; Cajanus cajan; fitomassa.

áreas tem conduzido à necessidade do uso de práticas de adição de matéria orgânica ao solo (Alcântara et al. 2000). Dentre estas, destaca-se a adubação verde, frequentemente associada à manutenção e/ou melhoria das condições físicas, químicas e biológicas do solo.

1. Trabalho recebido em jul./2009 e aceito para publicação em dez./2010 (nº registro: PAT 6777/ DOI: 10.5216/pat.v40i4.6777).

2. Universidade Estadual Paulista "Júlio de Mesquita Filho" (Unesp), Campus Experimental de Registro, Registro, SP, Brasil.E-mail: judlima@registro.unesp.br.

3. Universidade de São Paulo (USP), Escola Superior de Agricultura, Departamento de Produção Vegetal, Piracicaba, SP, Brasil.E-mail: ronaldosakai@usp.br.

4. Itograss Agrícola, Goiânia, GO, Brasil.E-mail:michel@itograss.com.br.

5. Agência Paulista de Tecnologia dos Agronegócios (APTA), Pólo Vale do Ribeira, Registro, SP, Brasil. 
Leguminosas têm sido as espécies mais utilizadas para esta finalidade, pelo fato de estabelecerem associação simbiótica com bactérias fixadoras do nitrogênio do ar, do gênero Rhizobium e Bradyrhizobium, resultando no aporte de quantidades expressivas deste nutriente (Perin et al. 2003). Além disto, apresentam sistema radicular profundo e ramificado, capaz de extrair nutrientes das camadas mais profundas do solo (Alcântara et al. 2000). Outra vantagem, é a rápida decomposição de seus resíduos, em decorrência da baixa relação $\mathrm{C} / \mathrm{N}$, determinando, assim, a rápida taxa de liberação de nitrogênio (Aita et al. 2001) e outros nutrientes (Perin et al. 2003, Salmi et al. 2006, Susuki \& Alves 2006), que podem ser aproveitados pela cultura subsequente (Aita et al. 2001, Fontanétti et al. 2006, Jesus et al. 2007, Andrioli et al. 2008, Duarte Júnior \& Coelho 2008). Contudo, a resposta à adubação verde depende da interação de fatores como natureza do material utilizado, práticas de manejo, condições climáticas locais, características do solo e da cultura subsequente (Lal 1986, De-Polli \& Chada 1989).

Crotalaria juncea, Cajanus cajan e Mucuna deeringiana são leguminosas tropicais, fixadoras de nitrogênio, que apresentaram desempenho satisfatório, para utilização como adubo verde, em diversos estudos (Alcântara et al. 2000, Silva et al. 2002, Menezes \& Leandro 2004, Nascimento \& Silva 2004, Susuki \& Alves 2006). Crotalaria juncea e Cajanus cajan têm porte arbustivo ereto, enquanto Mucuna deeringiana tem porte herbáceo. Crotalaria juncea e Mucuna deeringiana são espécies de ciclo curto, com florescimento em torno de 110 dias, e Cajanus cajan é uma espécie de ciclo longo, com florescimento após 140 dias (Silva et al. 2002). Todas são espécies sensíveis ao fotoperíodo, iniciando a floração em resposta aos dias curtos (Qi et al. 1999, Carberry et al. 2001).

Devido às diferentes características destas espécies, é provável que a interação genótipo x latitude ou espaçamento ou densidade de semeadura ou, ainda, época de semeadura influencie a produção de matéria seca e acúmulo de nutrientes. Assim sendo, o conhecimento destas interações permite a adoção de um conjunto de práticas de manejo mais adequado, que contribua para que a comunidade de plantas tenha o melhor aproveitamento possível dos recursos ambientais disponíveis e, consequentemente, melhor desempenho de adubos verdes.

Diante do exposto, o presente trabalho objetivou avaliar o efeito da densidade de semeadura, do arranjo espacial e da época de semeadura na acumulação de matéria seca e nutrientes em Crotalaria juncea, Mucuna deeringiana e Cajanus cajan, em Pariquera-Açu, Vale do Ribeira (SP).

\section{MATERIAL E MÉTODOS}

Os experimentos foram instalados no ano agrícola 2005/2006, em área experimental da Agência Paulista de Tecnologia e Agronegócios (APTA), Pólo Regional do Vale do Ribeira, em Pariquera-Açu, SP ( $24^{\circ} 35^{\prime} \mathrm{S}, 47^{\circ} 50^{\prime} \mathrm{W}$ e altitude de $25 \mathrm{~m}$ ). Segundo a classificação Köppen, o clima da região é tropical úmido Af, com transição para $\mathrm{Cfa}$, sem estação seca definida. Durante o período experimental, foram registradas as temperaturas máxima e mínima e a precipitação pluvial diárias (Figura 1).

O solo da área experimental é caracterizado como Latossolo Vermelho-Amarelo (Sakai \& Lepsch 1984), cuja análise química da camada $0-0,2 \mathrm{~m}$ de profundidade resultou em $\mathrm{pH}$ em $\mathrm{CaCl}_{2}=4,6$; teor de matéria orgânica $=22 \mathrm{~g} \mathrm{dm}^{-3} ; \mathrm{P}=6 \mathrm{mg} \mathrm{dm}^{-3} ; \mathrm{K}=$ $0,12 \mathrm{cmol}_{\mathrm{c}} \mathrm{dm}^{-3} ; \mathrm{Ca}=2 \mathrm{cmol}_{\mathrm{c}} \mathrm{dm}^{-3} ; \mathrm{Mg}=1 \mathrm{cmol}_{\mathrm{c}}$ $\mathrm{dm}^{-3} ; \mathrm{S}_{-} \mathrm{SO}_{4}^{-}=7 \mathrm{mg} \mathrm{dm}^{-3} ; \mathrm{H}+\mathrm{Al}=4,7 \mathrm{cmol}_{\mathrm{c}} \mathrm{dm}^{-3} \mathrm{e}$ $\mathrm{Al}=0,3 \mathrm{cmol}_{\mathrm{c}} \mathrm{dm}^{-3}$. O preparo do solo consistiu em uma aração, seguida de grade niveladora. Foram conduzidos três experimentos, utilizando-se as espécies de adubos verdes Crotalaria juncea cv. IAC KR1(crotalária), Mucuna deeringiana cv. Comum (mucuna) e Cajanus cajan cv. Kaki (guandu). Em nenhum dos experimentos foram efetuadas calagem, adubação e irrigação e em todos foi realizada semeadura manual.

O primeiro experimento foi realizado com o objetivo de determinar o efeito da densidade de semeadura na produção de matéria seca e acúmulo de nutrientes dos adubos verdes. O delineamento experimental utilizado foi o de blocos ao acaso, em esquema fatorial $3 \times 2$, com três espécies de adubos verdes e duas densidades de semeadura (500.000 e 625.000 plantas ha $^{-1}$ para crotalária, 160.000 e 200.000 plantas ha ${ }^{-1}$ para mucuna e 320.000 e 400.000 plantas ha ${ }^{-1}$ para guandu) e quatro repetições, representadas por parcelas de $20 \mathrm{~m}^{2}$. As diferentes densidades de semeadura foram obtidas por meio da utilização de dois espaçamentos na entrelinha $(0,5 \mathrm{~m}$ e $0,4 \mathrm{~m})$, utilizados por grande parte dos produtores de outras culturas na região, o que, segundo Amabile et al. (2000), facilitaria a mecanização na semeadura de adubos verdes. A semeadura foi realizada em 15/11/2005. 


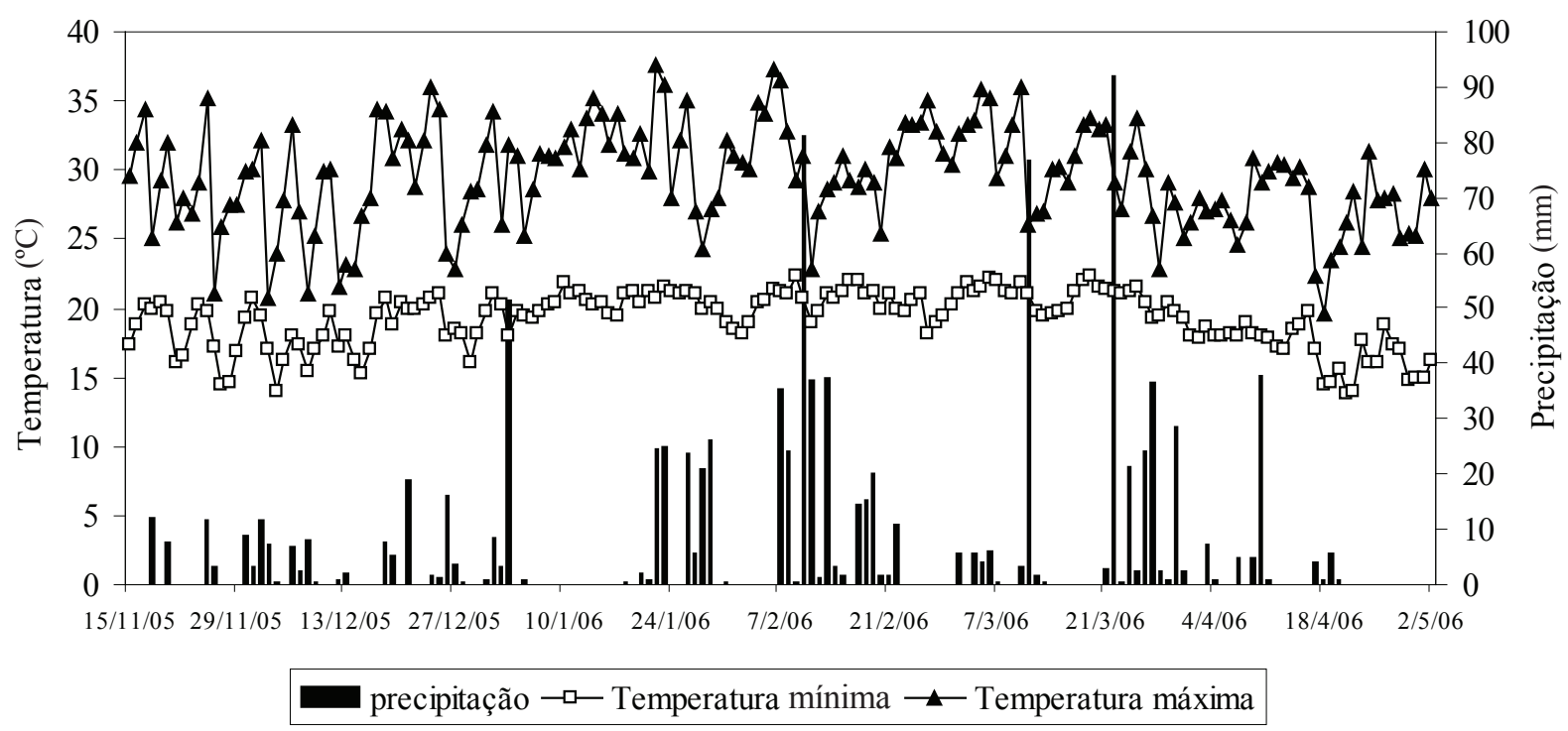

Figura 1. Temperatura máxima, mínima e precipitação pluviométrica diárias, durante a condução dos experimentos (Pariquera-Açu, SP, 2005/2006)

No segundo experimento, foi determinado o efeito do arranjo espacial na acumulação de matéria seca e nutrientes. $\mathrm{O}$ delineamento experimental utilizado foi o de blocos ao acaso, em esquema fatorial $3 \times 2$, sendo três espécies de adubos verdes e dois espaçamentos na entrelinha $(0,5 \mathrm{~m}$ e $0,4 \mathrm{~m})$ e quatro repetições, representadas por parcelas de $20 \mathrm{~m}^{2}$. A semeadura foi realizada em 15/11/2005, mantendo-se as densidades de semeadura mais baixas iguais a $500.000,160.000$ e 320.000 plantas $^{-1}$, respectiva- $^{-}$ mente, para crotalária, mucuna e guandu, para evitar a ocorrência de competição.

O terceiro experimento objetivou a determinação do efeito de épocas de semeadura no número de dias para os adubos verdes atingirem $50 \%$ de florescimento, bem como a produção de matéria seca e o acúmulo de nutrientes. $\mathrm{O}$ delineamento experimental utilizado foi o de blocos casualizados, em parcelas subdivididas. As parcelas constituíram as quatro épocas de semeadura $(15 / 11 / 05,02 / 01 / 06$, 14/02/06 e 18/03/06) e as subparcelas as espécies de adubos verdes, em quatro repetições, representada, cada uma, por área de $20 \mathrm{~m}^{2}$. A densidade de semeadura foi de $500.000,160.000$ e 320.000 plantas ha $^{-1}$, respectivamente, para crotalária, mucuna e guandu.

Nos três experimentos, quando as plantas atingiram $50 \%$ de floração, foram determinados a matéria seca e o acúmulo de macronutrientes $(\mathrm{N}$, $\mathrm{P}, \mathrm{K}, \mathrm{Ca}, \mathrm{Mg}$ e S), micronutrientes (Fe, Mn, B, Zn e $\mathrm{Cu}$ ) e carbono orgânico da parte aérea. Para tal, foram coletadas amostras de um metro quadrado das plantas cortadas rente ao solo, que foram secas em estufa, a $75^{\circ} \mathrm{C}$, até atingirem peso constante, e, em seguida, pesadas. Parte do material seco foi moída, em moinho, e submetida a análise química, para determinação dos teores de nutrientes, sendo as análises realizadas na Faculdade de Ciências Agronômicas de Botucatu (Unesp), de acordo com método descrito por Malavolta (1967). O acúmulo de macro e micronutrientes foi obtido pelo produto da quantidade de matéria seca com o teor dos nutrientes da parte aérea do adubo verde. No terceiro experimento, também foi determinado o número de dias para as plantas atingirem florescimento pleno, a partir da semeadura.

Os dados obtidos foram submetidos a análise de variância e as médias comparadas pelo teste Tukey, a $5 \%$ de probabilidade.

\section{RESULTADOS E DISCUSSÃO}

\section{Densidade de semeadura}

Durante o primeiro experimento, as temperaturas mantiveram-se entre $14^{\circ} \mathrm{C}$ e $37,6^{\circ} \mathrm{C}$, com média de $24,9^{\circ} \mathrm{C}$, e a precipitação total acumulada foi de $726,1 \mathrm{~mm}$ (Figura 1). Nestas condições, não houve diferenças no número de dias para mucuna e crotalária atingirem $50 \%$ de florescimento, nas duas densidades de semeadura. Nas mesmas condições, o guandu não apresentou florescimento. 
A crotalária, independentemente da densidade de semeadura, foi a espécie mais eficiente na acumulação de matéria seca (Tabela 1). Os maiores acúmulos de matéria seca pela crotalária e mucuna ocorreram na menor densidade de semeadura. No entanto, para o guandu, o decréscimo na acumulação de matéria seca, na densidade de semeadura mais alta, não foi significativo, quando comparado com o obtido na densidade de semeadura mais baixa. As reduções na acumulação de matéria seca, com a elevação da densidade de semeadura, foram de $8,4 \% ; 35,3 \%$; e 5,0\%, respectivamente, para crotalária, mucuna e guandu, demonstrando que guandu foi a espécie mais tolerante ao adensamento e mucuna a espécie mais sensível (Tabela 1). Estas diferenças podem ser atribuídas à arquitetura das espécies, uma vez que a mucuna apresenta hábito rasteiro e folhas maiores e mais planas do que a crotalária e o guandu, fatores que podem favorecer o sombreamento dentro do dossel, em densidade populacional mais alta, resultando no baixo acúmulo de matéria seca.

Tabela 1. Valores médios do acúmulo de matéria seca $\left(\mathrm{kg} \mathrm{ha}^{-1}\right)$, no primeiro experimento, em função de espécies de adubo verde e densidade de semeadura (Pariquera-Açu, SP, 2005/2006).

\begin{tabular}{cccc}
\hline \multirow{2}{*}{$\begin{array}{c}\text { Densidade de } \\
\text { semeadura }\end{array}$} & \multicolumn{3}{c}{ Acúmulo de matéria seca } \\
\cline { 2 - 4 } & Crotalária & Mucuna & Guandu \\
\hline Baixa & $15.614 \mathrm{~A} \mathrm{a}$ & $8.469 \mathrm{Ag} \mathrm{b}$ & $9.798 \mathrm{~A} \mathrm{~b}$ \\
Alta & $14.303 \mathrm{~B} \mathrm{a}$ & $5.478 \mathrm{~B} \mathrm{c}$ & $9.305 \mathrm{~A} \mathrm{~b}$ \\
\hline
\end{tabular}

A densidade de semeadura baixa correspondeu a 500.000, 160.000 e 320.000 plantas ha ${ }^{-1}$, respectivamente, para crotalária, guandu e mucuna, e a densidade de semeadura alta correspondeu a $625.000,200.000$ e 400.000 plantas $\mathrm{ha}^{-1}$, respectivamente, para crotalária, guandu e mucuna.

Médias seguidas da mesma letra maiúscula, na coluna, e minúscula, na linha, não diferem entre si, a $5 \%$ de probabilidade, pelo teste Tukey.
Fernandes et al. (1999) também observaram pouca oscilação na acumulação de matéria seca no guandu, com o adensamento populacional, e, para mucuna rajada, menor incremento da matéria seca da parte aérea, em resposta ao adensamento populacional. Rowden et al. (1981) atribuíram o menor efeito da densidade de semeadura, na acumulação de matéria seca do guandu, ao baixo coeficiente de extinção, sugerindo que a estrutura do dossel foi eficiente, permitindo a penetração da luz.

A acumulação de todos os macronutrientes na parte aérea foi influenciada pela espécie de adubo verde (Tabela 2). A acumulação de N, P e S também foi afetada pela densidade de semeadura e, adicionalmente, a acumulação de $\mathrm{P}$ foi influenciada pela interação espécie de adubo verde $\mathrm{x}$ densidade de semeadura. A crotalária apresentou os valores mais elevados de acumulação de $\mathrm{N}, \mathrm{P}, \mathrm{K}, \mathrm{Ca}, \mathrm{Mg}$ e $\mathrm{S}$ (Tabela 2), provavelmente em decorrência da maior acumulação de matéria seca (Tabela 1). A mucuna, quando comparada com o guandu, acumulou mais $\mathrm{K}$ e S, enquanto o guandu acumulou mais $\mathrm{N}$ e $\mathrm{Mg}$, em relação à mucuna, não havendo diferenças entre estas espécies, no acúmulo de $\mathrm{P}$ e Ca.

Independentemente da espécie de adubo verde, na maior densidade de semeadura, a acumulação de $\mathrm{N}, \mathrm{P}$ e S foi, respectivamente, $21 \%, 17 \%$ e $23 \%$ menor, quando comparada com a acumulação observada na maior densidade de semeadura (Tabela 2). Para os demais macronutrientes ( $\mathrm{K}, \mathrm{Ca}$ e $\mathrm{Mg})$, o decréscimo na acumulação, promovido pelo aumento da densidade de semeadura, não foi significativo.

Não houve diferenças na acumulação de $\mathrm{P}$ pela crotalária, nas duas densidades de semeadura (Tabela 2). Contudo, o aumento da densidade de

Tabela 2. Acúmulo de macronutrientes $\left(\mathrm{kg} \mathrm{ha}^{-1}\right)$ e relação $\mathrm{C} / \mathrm{N}$ da matéria seca, no primeiro experimento, em função da espécie de adubo verde e densidade de semeadura (Pariquera-Açu, SP, 2005/2006).

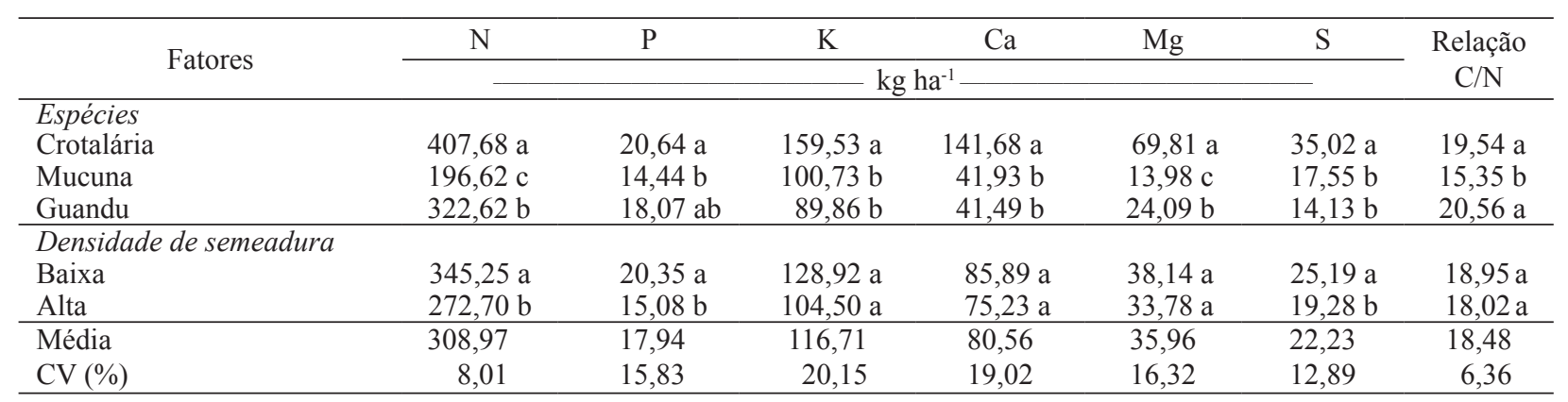

A densidade de semeadura baixa correspondeu a 500.000, 160.000 e 320.000 plantas ha ${ }^{-1}$, respectivamente, para crotalária, guandu e mucuna, e a densidade de semeadura alta correspondeu a $625.000,200.000$ e 400.000 plantas ha $^{-1}$, respectivamente, para crotalária, guandu e mucuna.

Médias seguidas da mesma letra maiúscula, na coluna, e minúscula, na linha, não diferem entre si, a 5\% de probabilidade, pelo teste Tukey. 
semeadura afetou, negativamente, a acumulação de $\mathrm{P}$ na mucuna e guandu. Isto demonstra a maior habilidade da crotalária no acúmulo deste elemento, quando comparada com as demais.

Independentemente da densidade de semeadura, a crotalária acumulou cerca de $16 \mathrm{tha}^{-1}$ de matéria seca; $407 \mathrm{~kg} \mathrm{ha}^{-1} \mathrm{de} \mathrm{N} ; 21 \mathrm{~kg} \mathrm{ha}^{-1} \mathrm{de}$ P; e $160 \mathrm{~kg} \mathrm{ha}^{-1}$ de K (Tabela 2). Ricci et al. (2005), trabalhando com a mesma espécie de adubo verde, semeada em novembro, observaram produção de 15 tha $^{-1}$ de matéria seca e a reciclagem de $444 \mathrm{~kg} \mathrm{ha}^{-1}$ de N; $21 \mathrm{~kg} \mathrm{ha}^{-1}$ de $\mathrm{P}$; e $241 \mathrm{~kg} \mathrm{ha}^{-1}$ de K. Portanto, para N e K, os valores foram próximos aos obtidos neste estudo.

Silva et al. (2002) verificaram acumulação de apenas 3,50 tha-1 de matéria seca; $92 \mathrm{~kg} \mathrm{ha}^{-1}$ de $\mathrm{N} ; 7 \mathrm{~kg} \mathrm{ha}^{-1}$ de P; e $46 \mathrm{~kg} \mathrm{ha}^{-1}$ de K, em Mucuna deeringiana, valores médios inferiores aos obtidos neste estudo, para a mesma espécie, que foram $7 \mathrm{tha}^{-1}$ de matéria seca; $195 \mathrm{~kg} \mathrm{ha}^{-1}$ de N; $14 \mathrm{~kg} \mathrm{ha}^{-1}$ de P; e $101 \mathrm{~kg} \mathrm{ha}^{-1}$ de K (Tabela 2).

Salmi et al. (2006) verificaram, em guandu, acumulação de matéria seca da ordem de $5,9 \mathrm{t} \mathrm{ha}^{-1}$ e acúmulo de $\mathrm{N}$ variando de $188,3 \mathrm{~kg} \mathrm{ha}^{-1}$ a 261,3 $\mathrm{kg} \mathrm{ha}^{-1}$; P de 7,2 $\mathrm{kg} \mathrm{ha}^{-1}$ a 9,4 $\mathrm{kg} \mathrm{ha}^{-1}$; e K de 29,3 $\mathrm{kg} \mathrm{ha}^{-1}$ a 45,5 $\mathrm{kg} \mathrm{ha}^{-1}$. O acúmulo dos mesmos nutrientes, neste estudo, foi bem mais elevado, sendo, respectivamente, de $322 \mathrm{~kg} \mathrm{ha}^{-1}, 18 \mathrm{~kg} \mathrm{ha}^{-1}$ e $90 \mathrm{~kg} \mathrm{ha}^{-1}$, para N, P e K, e um total de cerca de $9,5 \mathrm{t} \mathrm{ha}^{-1}$ de matéria seca, independentemente da densidade de semeadura.

Crotalária e guandu apresentaram as relações $\mathrm{C} / \mathrm{N}$ mais elevadas, respectivamente, de 19,54 e 20,56, não diferindo entre si, e superiores à relação $\mathrm{C} / \mathrm{N}$ da mucuna, que foi igual a 15,35 (Tabela 2), valores médios próximos aos observados em outros trabalhos, para guandu (Favero et al. 2000), bem como para crotalária e mucuna (Torres et al. 2005). Estes resultados podem estar relacionados ao fato de a crotalária e o guandu apresentarem valores de acumulação de matéria seca mais altos no caule, que, normalmente, possui valores mais altos de relação $\mathrm{C} / \mathrm{N}$, enquanto a mucuna apresenta maior acumulação nas folhas, que possuem relação $\mathrm{C} / \mathrm{N}$ mais baixa, como consequência de o seu teor de $\mathrm{N}$ ser mais elevado (Palm et al. 2001).

$\mathrm{O}$ acúmulo de todos os micronutrientes analisados ( $\mathrm{Fe}, \mathrm{Mn}, \mathrm{B}, \mathrm{Zn}$ e $\mathrm{Cu}$ ) foi influenciado pela espécie de adubo verde, enquanto o acúmulo de $\mathrm{Fe}$, $\mathrm{B}, \mathrm{Zn}$ e Cu também foram influenciados pela densidade de semeadura (Tabela 3). Apenas para B e Zn, a acumulação foi influenciada pela interação espécie de adubo verde $\mathrm{x}$ densidade de semeadura (Tabela 3 ).

Com exceção do Mn, cuja acumulação não foi influenciada pela densidade de semeadura, e do Fe, cuja acumulação foi mais elevada em alta densidade de semeadura, provavelmente pelo efeito da concentração, a acumulação dos demais micronutrientes foi reduzida, com o aumento da densidade de semeadura (Tabela 3). $\mathrm{O}$ acúmulo de $\mathrm{B}$ e Z, na crotalária e mucuna, foi mais baixo na maior densidade de semeadura, enquanto o guandu não sofreu influência da densidade de semeadura.

A redução no acúmulo de matéria seca, $\mathrm{N}, \mathrm{P}$, $\mathrm{S}, \mathrm{B}, \mathrm{Zn}$ e $\mathrm{Cu}$, com o aumento da densidade de semeadura, pode ser atribuída a uma menor exploração do solo pelas raízes, colaborando para que houvesse competição mais intensa por nutrientes e água, bem como menor interceptação de luz pelas folhas e aumento de autosombreamento no dossel.

Tabela 3. Acúmulo de micronutrientes $\left(\mathrm{g} \mathrm{ha}^{-1}\right)$ na matéria seca, no primeiro experimento, em função da espécie de adubo verde e densidade de semeadura (Pariquera-Açu, SP, 2005/2006).

\begin{tabular}{|c|c|c|c|c|c|}
\hline \multirow{2}{*}{ Fatores } & $\mathrm{Fe}$ & $\mathrm{Mn}$ & $\mathrm{B}$ & $\mathrm{Zn}$ & $\mathrm{Cu}$ \\
\hline & \multicolumn{5}{|c|}{$\mathrm{g} \mathrm{ha}^{-1}$} \\
\hline \multicolumn{6}{|c|}{ 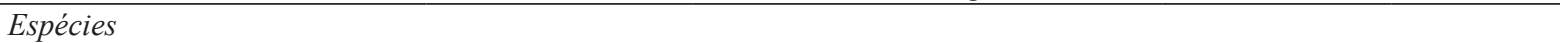 } \\
\hline Crotalária & $4.072,01 \mathrm{a}$ & $1.295,97 \mathrm{a}$ & $361,62 \mathrm{a}$ & 387,98 a & $105,04 \mathrm{a}$ \\
\hline Mucuna & $1.326,70 \mathrm{~b}$ & $530,88 \mathrm{~b}$ & $220,21 \mathrm{~b}$ & $121,42 \mathrm{c}$ & $58,66 \mathrm{~b}$ \\
\hline Guandu & $835,34 \mathrm{~b}$ & $416,70 \mathrm{~b}$ & $220,55 \mathrm{~b}$ & $190,90 \mathrm{~b}$ & $67,96 \mathrm{~b}$ \\
\hline \multicolumn{6}{|c|}{ Densidade de semeadura } \\
\hline Baixa & $1.604,83 \mathrm{~b}$ & 844,16 a & $298,17 \mathrm{a}$ & $270,64 \mathrm{a}$ & $85,67 \mathrm{a}$ \\
\hline Alta & $2.551,10 \mathrm{a}$ & $651,54 \mathrm{a}$ & $247,40 \mathrm{~b}$ & $196,23 \mathrm{~b}$ & $68,77 \mathrm{~b}$ \\
\hline Média & $1.604,83$ & 747,85 & 272,79 & 233,44 & 77,22 \\
\hline $\mathrm{CV}(\%)$ & 20,18 & 17,45 & 6,35 & 5,69 & 18,58 \\
\hline
\end{tabular}

A densidade de semeadura baixa correspondeu a 500.000, 160.000 e 320.000 plantas ha ${ }^{-1}$, respectivamente, para crotalária, guandu e mucuna, e a densidade de semeadura alta correspondeu a 625.000, 200.000 e 400.000 plantas ha $^{-1}$, respectivamente, para crotalária, guandu e mucuna.

Médias seguidas da mesma letra maiúscula, na coluna, e minúscula, na linha, não diferem entre si, a $5 \%$ de probabilidade, pelo teste Tukey. 


\section{Arranjo espacial}

Não houve efeito do arranjo espacial (espaçamento) e da interação entre o arranjo espacial e a espécie de adubo verde, no acúmulo de matéria seca (Tabela 4), o mesmo ocorrendo para acumulação de macronutrientes (N, P, K, Ca, Mg e S) e micronutrientes (Fe, Mn, B, Zn e Cu). Amabile et al. (2000) também não observaram efeito dos espaçamentos $0,4 \mathrm{~m}$ e $0,5 \mathrm{~m}$ na entrelinha, na produção de matéria seca de crotalária e guandu. No entanto, cada espécie de adubo verde teve seu acúmulo particular de matéria seca e nutrientes, sendo a crotalária a espécie mais eficiente (Tabela 4). Entre mucuna e guandu, não houve diferenças no acúmulo de matéria seca, $\mathrm{P}, \mathrm{K}$, $\mathrm{Ca}, \mathrm{S}, \mathrm{Fe}$ e $\mathrm{Mn}$, enquanto, para $\mathrm{Ne} \mathrm{Mg}$, o acúmulo foi mais elevado no guandu e, para B e Zn, na mucuna.

Rao \& Gill (1995) observaram que guandu apresenta excelente adaptabilidade à variação da distância entre linhas $(0,3-0,12 \mathrm{~m})$ ou entre plantas $(0,3-$ $0,9 \mathrm{~m}$ ) e que o fator determinante para produção de matéria seca não foi o espaçamento, mas a população de plantas por hectare. Os diferentes arranjos espaciais também não influenciaram os teores de nutrientes nas folhas ou caule, em diferentes estádios de crescimento.

Os principais fatores que determinam a acumulação de matéria seca são a interceptação da radiação solar pelas folhas do dossel da cultura e a utilização desta radiação interceptada. Segundo Pires et al. (1998), com a redução no espaçamento entre linhas, podem ser acarretadas modificações na área foliar e no índice de área foliar e, como consequência, na quantidade de matéria seca acumulada pelas plantas (Scott \& Aldrich 1975).
A ausência de efeito do arranjo espacial, nas variáveis analisadas, indica que a interceptação de luz não foi modificada, de maneira significativa, com as alterações na disposição das plantas. Uma vez que não ocorreram diferenças no acúmulo de $\mathrm{N}$, na matéria seca dos adubos verdes, em função do arranjo espacial, pode-se dizer que, além da fotossíntese, a fixação biológica do nitrogênio não foi afetada.

\section{Época de semeadura}

A época de semeadura influencia o crescimento, desenvolvimento e interação entre crescimento e desenvolvimento e períodos de estresse. Portanto, é um dos principais determinantes da produtividade das culturas, sendo a sua escolha influenciada por fatores ambientais. Assim, o entendimento da fenologia e a determinação da época de semeadura mais adequada aos adubos verdes, para determinada região (ambiente alvo), são de fundamental importância para a exploração do seu máximo potencial.

No presente estudo, o número de dias para a crotalária atingir $50 \%$ de florescimento foi reduzido na segunda, terceira e quarta semeaduras, em relação à primeira semeadura (Tabela 5). Para mucuna, não houve diferença no número de dias para atingir 50\% de florescimento entre a primeira e segunda épocas de semeadura, ambas diferindo das demais épocas. Para guandu, foi observado florescimento apenas na quarta época de semeadura (Tabela 5).

Na primeira época de semeadura, a crotalária foi a espécie que apresentou maior acúmulo de matéria seca, não havendo diferenças entre guandu e mucuna. Na segunda época de semeadura, guandu foi

Tabela 4. Valores médios do acúmulo de matéria seca $\left(\mathrm{kg} \mathrm{ha}^{-1}\right)$ e do acúmulo de macro $\left(\mathrm{g} \mathrm{kg}^{-1}\right)$ e micronutrientes $\left(\mathrm{g} \mathrm{ha}^{-1}\right)$, no segundo experimento, em função de espécies de adubo verde (Pariquera-Açu, SP, 2005/2006).

\begin{tabular}{lrrrrr}
\hline & Crotalária & Mucuna & Guandu & Média & CV $(\%)$ \\
\hline Matéria seca $\left(\mathrm{kg} \mathrm{ha}^{-1}\right)$ & $15.344,02 \mathrm{a}$ & $9.155,74 \mathrm{~b}$ & $9.782,06 \mathrm{~b}$ & $11.427,03$ & 6,69 \\
$\mathrm{~N}\left(\mathrm{~g} \mathrm{~kg}^{-1}\right)$ & $443,29 \mathrm{a}$ & $210,19 \mathrm{c}$ & $336,60 \mathrm{~b}$ & 330,03 & 10,25 \\
$\mathrm{P}\left(\mathrm{g} \mathrm{kg}^{-1}\right)$ & $28,57 \mathrm{a}$ & $19,41 \mathrm{~b}$ & $18,88 \mathrm{~b}$ & 22,29 & 9,86 \\
$\mathrm{~K}\left(\mathrm{~g} \mathrm{~kg}^{-1}\right)$ & $143,00 \mathrm{a}$ & $138,98 \mathrm{a}$ & $95,08 \mathrm{~b}$ & 125,70 & 6,18 \\
$\mathrm{Ca}\left(\mathrm{g} \mathrm{kg}^{-1}\right)$ & $78,65 \mathrm{a}$ & $48,40 \mathrm{~b}$ & $45,92 \mathrm{~b}$ & 57,52 & 10,24 \\
$\mathrm{Mg}\left(\mathrm{g} \mathrm{kg}^{-1}\right)$ & $78,71 \mathrm{a}$ & $16,02 \mathrm{c}$ & $31,79 \mathrm{~b}$ & 42,17 & 4,26 \\
$\mathrm{~S}\left(\mathrm{~g} \mathrm{~kg}^{-1}\right)$ & $36,98 \mathrm{a}$ & $17,40 \mathrm{~b}$ & $18,10 \mathrm{~b}$ & 24,16 & 4,87 \\
$\mathrm{Fe}\left(\mathrm{g} \mathrm{ha}^{-1}\right)$ & $3.858,41 \mathrm{a}$ & $1.423,38 \mathrm{~b}$ & $1.203,37 \mathrm{~b}$ & $2.161,72$ & 5,69 \\
$\mathrm{Mn}\left(\mathrm{g} \mathrm{ha}^{-1}\right)$ & $1.354,75 \mathrm{a}$ & $537,25 \mathrm{~b}$ & $521,37 \mathrm{~b}$ & 804,56 & 9,69 \\
$\mathrm{~B}\left(\mathrm{~g} \mathrm{ha}^{-1}\right)$ & $410,45 \mathrm{a}$ & $312,39 \mathrm{~b}$ & $315,88 \mathrm{c}$ & 346,24 & 6,21 \\
$\mathrm{Zn}\left(\mathrm{g} \mathrm{ha}^{-1}\right)$ & $461,47 \mathrm{a}$ & $324,50 \mathrm{~b}$ & $164,24 \mathrm{c}$ & 316,74 & 12,58 \\
$\mathrm{Cu}\left(\mathrm{g} \mathrm{ha}^{-1}\right)$ & $125,05 \mathrm{a}$ & $75,35 \mathrm{~b}$ & $77,47 \mathrm{~b}$ & 92,62 & 2,56 \\
\hline
\end{tabular}

Médias seguidas da mesma letra, na linha, não diferem entre si, a 5\% de probabilidade, pelo teste Tukey. 
Tabela 5. Valores médios do número de dias após a semeadura, para atingir 50\% do florescimento e acúmulo de matéria seca $\left(\mathrm{kg} \mathrm{ha}^{-1}\right)$, no terceiro experimento, em função de espécies de adubo verde e época de semeadura (Pariquera-Açu, SP, 2005/2006).

\begin{tabular}{|c|c|c|c|c|}
\hline \multirow{3}{*}{ Espécies } & \multicolumn{4}{|c|}{ Épocas de semeadura } \\
\hline & $\begin{array}{c}1^{\mathrm{a}} \text { época } \\
(15 / 11 / 2005)\end{array}$ & $\begin{array}{c}2^{\mathrm{a}} \text { época } \\
(02 / 01 / 2006)\end{array}$ & $\begin{array}{c}3^{\mathrm{a}} \text { época } \\
(14 / 02 / 2006)\end{array}$ & $\begin{array}{c}4^{\mathrm{a}} \text { época } \\
(18 / 03 / 2006)\end{array}$ \\
\hline & \multicolumn{4}{|c|}{$\mathrm{N}^{\mathrm{o}}$ de dias para florescimento } \\
\hline Crotalária & $116 \mathrm{a}$ & $90 \mathrm{~b}$ & $53 \mathrm{c}$ & $50 \mathrm{c}$ \\
\hline Mucuna & $110 \mathrm{a}$ & $92 \mathrm{a}$ & $46 \mathrm{~b}$ & $45 \mathrm{~b}$ \\
\hline \multirow[t]{2}{*}{ Guandu } & Sem flor & Sem flor & Sem flor & 46 \\
\hline & \multicolumn{4}{|c|}{ Matéria seca $\left(\mathrm{kg} \mathrm{ha}^{-1}\right)$} \\
\hline Crotalária & $15.614 \mathrm{~A} \mathrm{a}$ & $7.651 \mathrm{~B} \mathrm{~b}$ & $4.615 \mathrm{~A} \mathrm{c}$ & $1.094 \mathrm{~A} \mathrm{~d}$ \\
\hline Mucuna & $8.469 \mathrm{~B} \mathrm{a}$ & $7.896 \mathrm{~B} \mathrm{a}$ & $1.640 \mathrm{~B} \mathrm{~b}$ & $759 \mathrm{Ab}$ \\
\hline Guandu & $9.798 \mathrm{~B} \mathrm{a}$ & $10.051 \mathrm{~A} \mathrm{a}$ & $2.934 \mathrm{~B} \mathrm{~b}$ & $950 \mathrm{Ab}$ \\
\hline
\end{tabular}

Médias seguidas da mesma letra maiúscula, na coluna, e minúscula, na linha, não diferem entre si, a 5\% de probabilidade, pelo teste Tukey.

a espécie que acumulou mais matéria seca, seguida da mucuna e crotalária, que não diferiram entre si. $\mathrm{Na}$ terceira época de semeadura, a crotalária foi a espécie que apresentou maior acúmulo de matéria seca, não havendo diferenças entre guandu e mucuna. Na quarta época de semeadura, não houve diferenças entre as três espécies, quanto ao acúmulo de matéria seca (Tabela 5). Amabile et al. (2000) também observaram redução de matéria seca, com o atraso da semeadura da crotalária e guandu.

O decréscimo no acúmulo de matéria seca da crotalária, com o atraso na semeadura, provavelmente esteja relacionado ao fato de a mesma ser planta de dia curto (Keatinge et al. 1998). Guandu é, também, sensível ao fotoperíodo e tem resposta qualitativa ao florescimento em dias curtos (Carberry et al. 2001), além de apresentar resistência à seca e melhor desenvolvimento em temperaturas mais elevadas (Mitidieri 1983, Seiffert \& Thiago 1983).

Os valores de temperatura média e precipitação total acumulada, para primeira, segunda, terceira e quarta época de semeadura, foram, respectivamente, $726,1 \mathrm{~mm}$ e $24,9^{\circ} \mathrm{C} ; 845,3 \mathrm{~mm}$ e $25,3^{\circ} \mathrm{C} ; 454,2 \mathrm{~mm}$ e $24,6^{\circ} \mathrm{C}$; e $299,8 \mathrm{~mm}$ e $21,0^{\circ} \mathrm{C}$ (Figura 1). Portanto, ocorreram variações significativas na precipitação acumulada nos dois últimos ciclos de cultivos, contra discretas variações na temperatura média, quando se consideram os quatro ciclos de cultivo.

A sensibilidade ao fotoperíodo foi demonstrada pela redução do número de dias para as plantas atingirem $50 \%$ do florescimento, com o deslocamento da época considerada como favorável para a semeadura (novembro) para datas marginais (janeiro, fevereiro e março), quando os dias tornaram-se curtos e causaram, assim, a diminuição da fase vegetativa das espécies. Com base na redução do ciclo vegetativo, pode-se dizer que as cultivares de crotalária e mucuna estudadas apresentam resposta fotoperiódica do tipo quantitativa, ou seja, o encurtamento do dia favorece a indução ao florescimento. A mesma reposta foi observada em crotalária, por Santos \& Campelo Júnior (2003) e Amabile et al. (2000), quando a semeadura foi feita em épocas marginais, respectivamente, em Mato Grosso e Goiás.

A redução da matéria seca produzida pela crotalária foi observada em todas as semeaduras, quando comparadas com a realizada em novembro (Tabela 5). Mucuna e guandu mantiveram produção de matéria seca semelhante, quando se comparam primeira e segunda épocas de semeadura. Contudo, apresentaram redução na terceira e quarta semeaduras.

Além do fotoperíodo, o florescimento de leguminosas tropicais é afetado pelo estresse hídrico (Schultze-Kraft \& Keller-Grein 1999). A falta de água, além de acelerar o florescimento, influencia, negativamente, a taxa de crescimento da planta, o que, consequentemente, reduz a massa seca produzida. Ocorreram poucas variações na temperatura, ao longo das semeaduras. Todavia, houve reduções de cerca de $37 \%$ e $59 \%$, na precipitação total acumulada, respectivamente, na terceira e quarta semeaduras, em relação à primeira. Apesar de a caracterização do clima da região revelar elevada precipitação média anual e níveis históricos de precipitação altos, de outubro a abril, na região, no ano agrícola 2005/2006, as chuvas foram muitos escassas, a partir da segunda quinzena de abril, período que coincide com a terceira e quarta épocas de semeadura. Amabile et al. (1996) também observaram que o atraso da semeadura, em relação ao início da estação chuvosa, acelerou o flo- 
rescimento das leguminosas e reduziu os rendimentos de matéria seca de $C$. juncea e guandu.

O efeito do fotoperíodo, na acumulação de matéria seca de crotalária, ficou, indiretamente, evidenciado pelo fato de esta espécie ter apresentado menor matéria seca na segunda época de semeadura, mesmo com disponibilidade de água maior e temperatura média com pouca variação, neste período de cultivo, em relação à primeira época de semeadura (Tabela 5).

Ocorreram reduções significativas no acúmulo de N, P, K, Ca e S, na parte aérea da crotalária, com o atraso na semeadura (Tabela 6). Para Mg, o acúmulo foi mais alto na primeira semeadura e mais baixo na segunda e terceira semeaduras, que não diferiram entre si, seguidas da quarta semeadura.

Na mucuna, não houve diferença na acumulação de macronutrientes, entre plantas da primeira e segunda semeadura, sendo seus valores de acumulação superiores às demais semeaduras. Apenas para o acúmulo de $\mathrm{N}$ e $\mathrm{K}$, a redução na acumulação em plantas cultivadas na terceira e quarta semeadura foi significativa (Tabela 6). No guandu, exceto para $\mathrm{Mg}$, o acúmulo dos demais macronutrientes foi significativamente mais baixo na quarta semeadura, em relação à primeira. Estas reduções, provavelmente, ocorreram em decorrência da maior disponibilidade de água, cuja absorção está diretamente relacionada com a absorção dos nutrientes. A época de semeadura não afetou a relação $\mathrm{C} / \mathrm{N}$.

$\mathrm{Na}$ crotalária, o atraso na semeadura promoveu reduções significativas no acúmulo de todos os micronutrientes (Tabela 7). Na mucuna, para Fe, B, Zn e
$\mathrm{Cu}$, os maiores acúmulos ocorreram na segunda época de semeadura, seguida da primeira e das demais épocas (Tabela 7), o que pode ser consequência da maior disponibilidade hídrica. No guandu, não houve diferenças no acúmulo dos micronutrientes, entre a primeira e segunda época de semeadura, sendo que, nas demais, os valores de acúmulo foram cada vez mais baixos, com o atraso na semeadura.

Para as três espécies, o atraso na semeadura, especialmente para fevereiro e março, prejudica o acúmulo de matéria seca e nutrientes e, consequentemente, o desempenho como adubo verde.

\section{CONCLUSÕES}

1. Densidades de semeadura altas reduzem o acúmulo de matéria seca, B e Zn, em Crotalaria juncea e Mucuna deeringiana; $\mathrm{o}$ acúmulo de $\mathrm{P}$, em Mucuna deeringiana e Cajanus cajan; e o acúmulo de N, $\mathrm{S}$ e $\mathrm{Cu}$, em todos os adubos verdes.

2. O arranjo espacial, obtido com o uso de espaçamento $0,4 \mathrm{~m}$ ou $0,5 \mathrm{~m}$, nas entrelinhas, não afeta o acúmulo de matéria seca e nutrientes da parte aérea dos adubos verdes.

3. Com base no acúmulo de matéria seca e nutrientes, Crotalaria juncea é a espécie mais eficiente para uso como adubo verde, quando semeada em novembro.

4. Crotalaria juncea, Mucuna deeringiana e Cajanus cajan apresentam baixo desempenho no acúmulo de matéria seca e nutrientes, quando semeadas em épocas tardias.

Tabela 6. Valores médios de acúmulo de macronutrientes $\left(\mathrm{g} \mathrm{kg}^{-1}\right)$ e relação $\mathrm{C} / \mathrm{N}$ na matéria seca, no terceiro experimento, em função da espécie de adubo verde e da época de semeadura (Pariquera-Açu, SP, 2005/2006).

\begin{tabular}{|c|c|c|c|c|c|c|c|c|}
\hline \multirow{2}{*}{ Espécie } & \multirow{2}{*}{ Época de semeadura } & $\mathrm{N}$ & $\mathrm{P}$ & $\mathrm{K}$ & $\mathrm{Ca}$ & $\mathrm{Mg}$ & $\mathrm{S}$ & \multirow{2}{*}{$\begin{array}{c}\text { Relação } \\
\text { C/N }\end{array}$} \\
\hline & & \multicolumn{6}{|c|}{$\mathrm{g} \mathrm{kg}^{-1}$} & \\
\hline \multirow{4}{*}{ Crotalária } & Primeira $(15 / 11 / 2005)$ & $407,68 \mathrm{a}$ & $20,64 \mathrm{a}$ & $159,53 \mathrm{a}$ & $141,68 \mathrm{a}$ & $69,81 \mathrm{a}$ & $35,02 \mathrm{a}$ & $19,54 \mathrm{a}$ \\
\hline & Segunda $(02 / 01 / 2006)$ & $177,28 \mathrm{~b}$ & $10,79 \mathrm{~b}$ & $93,73 b$ & $84,31 \mathrm{~b}$ & $37,95 \mathrm{~b}$ & $17,21 \mathrm{~b}$ & $19,22 \mathrm{a}$ \\
\hline & Terceira $(14 / 02 / 2006)$ & $85,93 \mathrm{c}$ & $4,52 \mathrm{c}$ & $42,60 \mathrm{c}$ & $33,78 \mathrm{c}$ & $21,68 \mathrm{~b}$ & $9,92 \mathrm{c}$ & $18,97 \mathrm{a}$ \\
\hline & Quarta $(18 / 03 / 2006)$ & $18,44 \mathrm{~d}$ & $0,86 \mathrm{~d}$ & $10,65 \mathrm{~d}$ & $5,48 \mathrm{~d}$ & $4,95 \mathrm{c}$ & $2,58 \mathrm{~d}$ & $18,02 \mathrm{a}$ \\
\hline \multirow{4}{*}{ Mucuna } & Primeira $(15 / 11 / 2005)$ & $196,62 \mathrm{a}$ & $14,44 \mathrm{a}$ & $100,73 \mathrm{a}$ & $41,93 \mathrm{a}$ & $13,98 \mathrm{a}$ & $17,55 \mathrm{a}$ & $15,35 \mathrm{a}$ \\
\hline & Segunda $(02 / 01 / 2006)$ & $233,40 \mathrm{a}$ & $16,98 \mathrm{a}$ & $110,39 \mathrm{a}$ & $47,45 \mathrm{a}$ & $16,74 \mathrm{a}$ & $15,87 \mathrm{a}$ & $16,01 \mathrm{a}$ \\
\hline & Terceira $(14 / 02 / 2006)$ & $46,26 \mathrm{~b}$ & $3,85 \mathrm{~b}$ & $24,19 \mathrm{~b}$ & $9,43 \mathrm{~b}$ & $3,35 \mathrm{~b}$ & $3,48 \mathrm{~b}$ & $15,93 \mathrm{a}$ \\
\hline & Quarta $(18 / 03 / 2006)$ & $18,21 \mathrm{c}$ & $1,86 \mathrm{~b}$ & $10,06 \mathrm{c}$ & $4,41 \mathrm{~b}$ & $1,60 \mathrm{~b}$ & $1,56 \mathrm{~b}$ & $16,02 \mathrm{a}$ \\
\hline \multirow{4}{*}{ Guandu } & Primeira $(15 / 11 / 2005)$ & $322,62 \mathrm{a}$ & $18,07 \mathrm{a}$ & $89,86 \mathrm{a}$ & $41,49 \mathrm{a}$ & $24,09 \mathrm{a}$ & $14,13 \mathrm{a}$ & $20,56 \mathrm{a}$ \\
\hline & Segunda $(02 / 01 / 2006)$ & $354,40 \mathrm{a}$ & $19,60 \mathrm{a}$ & $103,12 \mathrm{a}$ & $61,51 \mathrm{a}$ & $28,65 \mathrm{a}$ & $18,59 \mathrm{a}$ & $21,02 \mathrm{a}$ \\
\hline & Terceira $(14 / 02 / 2006)$ & $94,53 \mathrm{~b}$ & $5,37 \mathrm{~b}$ & $26,93 \mathrm{~b}$ & $16,52 \mathrm{~b}$ & $7,98 \mathrm{~b}$ & $5,13 \mathrm{~b}$ & $20,42 \mathrm{a}$ \\
\hline & Quarta $(18 / 03 / 2006)$ & $25,20 \mathrm{c}$ & $1,19 \mathrm{c}$ & $6,76 \mathrm{c}$ & $5,28 \mathrm{c}$ & $2,62 \mathrm{~b}$ & $1,69 \mathrm{c}$ & $20,35 \mathrm{a}$ \\
\hline Média & & 165,01 & 9,88 & 64,89 & 41,10 & 19,52 & 12,01 & 18,48 \\
\hline CV (\%) & & 10,23 & 6,53 & 5,38 & 12,63 & 5,55 & 2,85 & 15,78 \\
\hline
\end{tabular}

Médias seguidas da mesma letra, na coluna, para cada espécie de adubo verde, não diferem entre si, a 5\% de probabilidade, pelo teste Tukey. 
Tabela 7. Valores médios do acúmulo de micronutrientes $\left(\mathrm{g} \mathrm{ha}^{-1}\right)$ na matéria seca, no terceiro experimento, em função da espécie de adubo verde e da época de semeadura (Pariquera-Açu, SP, 2005/2006).

\begin{tabular}{|c|c|c|c|c|c|c|}
\hline \multirow{2}{*}{ Espécie } & \multirow{2}{*}{ Época de semeadura } & $\mathrm{Fe}$ & $\mathrm{Mn}$ & $\mathrm{B}$ & $\mathrm{Zn}$ & $\mathrm{Cu}$ \\
\hline & & \multicolumn{5}{|c|}{$\mathrm{g} \mathrm{ha}^{-1}$} \\
\hline \multirow{4}{*}{ Crotalária } & Primeira $(15 / 11 / 2005)$ & $4.072,01 \mathrm{a}$ & $1.295,97 \mathrm{a}$ & $361,62 \mathrm{a}$ & $387,98 \mathrm{a}$ & $105,04 \mathrm{a}$ \\
\hline & Segunda $(02 / 01 / 2006)$ & $1.936,86 \mathrm{~b}$ & $829,03 \mathrm{~b}$ & $187,60 \mathrm{~b}$ & $192,73 \mathrm{~b}$ & $53,94 \mathrm{~b}$ \\
\hline & Terceira $(14 / 02 / 2006)$ & $1.442,46 \mathrm{c}$ & $502,57 \mathrm{c}$ & $114,36 \mathrm{c}$ & $107,27 \mathrm{c}$ & $22,72 \mathrm{c}$ \\
\hline & Quarta $(18 / 03 / 2006)$ & $387,96 \mathrm{~d}$ & $118,59 \mathrm{~d}$ & $27,30 \mathrm{~d}$ & $29,01 \mathrm{~d}$ & $7,77 \mathrm{~d}$ \\
\hline \multirow{4}{*}{ Mucuna } & Primeira $(15 / 11 / 2005)$ & $1.326,70 \mathrm{~b}$ & $530,88 \mathrm{a}$ & $220,21 \mathrm{~b}$ & $121,42 b$ & $58,66 \mathrm{~b}$ \\
\hline & Segunda $(02 / 01 / 2006)$ & $1.678,77 \mathrm{a}$ & $535,23 \mathrm{a}$ & $248,33 \mathrm{a}$ & $159,03 \mathrm{a}$ & $76,22 \mathrm{a}$ \\
\hline & Terceira $(14 / 02 / 2006)$ & $452,57 \mathrm{c}$ & $320,16 \mathrm{c}$ & $72,27 \mathrm{c}$ & $32,95 \mathrm{c}$ & $21,48 \mathrm{c}$ \\
\hline & Quarta $(18 / 03 / 2006)$ & $223,96 \mathrm{c}$ & $112,99 \mathrm{c}$ & $23,63 \mathrm{~d}$ & $15,70 \mathrm{~d}$ & $5,35 \mathrm{~d}$ \\
\hline \multirow{4}{*}{ Guandu } & Primeira $(15 / 11 / 2005)$ & $835,34 \mathrm{a}$ & $416,80 \mathrm{a}$ & $220,55 \mathrm{a}$ & $190,90 \mathrm{a}$ & $67,96 \mathrm{a}$ \\
\hline & Segunda $(02 / 01 / 2006)$ & $858,86 \mathrm{a}$ & $389,97 \mathrm{a}$ & $251,48 \mathrm{a}$ & $192,98 \mathrm{a}$ & $71,92 \mathrm{a}$ \\
\hline & Terceira $(14 / 02 / 2006)$ & $368,39 \mathrm{~b}$ & $61,76 \mathrm{~b}$ & $73,55 \mathrm{~b}$ & $51,52 \mathrm{~b}$ & $23,65 \mathrm{~b}$ \\
\hline & Quarta $(18 / 03 / 2006)$ & $152,72 \mathrm{~b}$ & $59,85 \mathrm{~b}$ & $23,14 \mathrm{c}$ & $15,57 \mathrm{c}$ & $7,72 \mathrm{c}$ \\
\hline Média & & $1.144,52$ & 431,56 & 152,03 & 124,79 & 44,38 \\
\hline CV (\%) & & 13,63 & 4,75 & 9,18 & 12,25 & 5,69 \\
\hline
\end{tabular}

Médias seguidas da mesma letra, na coluna, para cada espécie de adubo verde, não diferem entre si, a 5\% de probabilidade, pelo teste Tukey.

\section{REFERÊNCIAS}

AITA, C. et al. Plantas de cobertura de solo como fonte de nitrogênio ao milho. Revista Brasileira de Ciência do Solo, Viçosa, v. 25, n. 1, p. 157-165, 2001.

ALCÂNTARA, F. A. de et al. Adubação verde na recuperação da fertilidade de um Latossolo vermelhoescuro. Pesquisa Agropecuária Brasileira, Brasília, DF, v. 35, n. 3, p. 277-288, 2000.

AMABILE, R. F. et al. Efeito de épocas de semeadura na fisiologia e produção de fitomassa de leguminosas nos cerrados da região do Matogrosso de Goiás. Scientia Agricola, Piracicaba, v. 53, n. 2/3, p. 296-303, 1996.

AMABILE, R. F.; FANCELLI, L.; CARVALHO, A. M. de. Comportamento de espécies de adubos verdes em diferentes épocas de semeadura e espaçamentos na região dos cerrados. Pesquisa Agropecuária Brasileira, Brasília, DF, v. 35, n. 1, p. 47-54, 2000.

ANDRIOLI, I. et al. Produção de milho em plantio direto com adubação nitrogenada e cobertura do solo na présafra. Revista Brasileira de Ciência do Solo, Viçosa, v. 32, n. 4, p. 1691-1698, 2008.

CARBERRY, P. S. et al. Predicting growth and development of pigeonpea: flowering response to photoperiod. Field Crops Research, Amsterdam, v. 69, n. 2, p. 151-162, 2001.

DE-POLLI, H.; CHADA, S. S. Adubação verde incorporada ou em cobertura na produção de milho em solo de baixo potencial de produtividade. Revista Brasileira de Ciência do Solo, Viçosa, v. 13, n. 3, p. 287-293, 1989.
DUARTE JÚNIOR, J. B.; COELHO, F. C. Adubos verdes e seus efeitos no rendimento da cana-de-açúcar em sistema de plantio direto. Bragantia, Campinas, v. 67, n. 3, p. 723$732,2008$.

FAVERO, C. et al. Crescimento e acúmulo de nutrientes por plantas espontâneas e por leguminosas utilizadas para adubação verde. Revista Brasileira de Ciência do Solo, Viçosa, v. 24, n. 1, p. 171-177, 2000.

FERNANDES, M. F.; BARRETO, A. C.; EMIDIO FILHO, J. Fitomassa de adubos verdes e controle de plantas daninhas em diferentes densidades populacionais de leguminosas. Pesquisa Agropecuária Brasileira, Brasília, DF, v. 34, n. 9, p. 1593-2000, 1999.

FONTANÉTTI, A. et al. Adubação verde na produção orgânica de alface americana e repolho. Horticultura Brasileira, Brasília, DF, v. 24, n. 2, p. 146-150, 2006.

JESUS, R. P. de et al. Plantas de cobertura de solo e seus efeitos no desenvolvimento da cultura do arroz de terras altas em cultivo orgânico. Pesquisa Agropecuária Tropical, Goiânia, v. 37, n. 4, p. 214-220, 2007.

KEATINGE, J. D. H. et al. Effects of temperature and photoperiod on phenology as a guide to the selection of annual legume cover and green manure crops for hillside farming systems. Field Crops Research, Amsterdam, v. 57, n. 2, p. 139-152, 1998.

LAL, R. No-tillage and surface-tillage systems to alleviate soil related constraints in the tropics. In: SPRAGUE, M. A.; TRIPLETT, G. B. No-tillage and surface-tillage agriculture. New York: Wiley, 1986. p. 261-317.

MALAVOLTA, E. Manual de química agrícola: adubos e adubação. São Paulo: Agronômica Ceres, 1967. 
MENEZES, L. A. S.; LEANDRO, W. M. Avaliação de espécies de coberturas do solo com potencial de uso em sistema de plantio direto. Pesquisa Agropecuária Tropical, Goiânia, v. 34, n. 3, p. 173-180, 2004.

MITIDIERI, J. Manual de graminea e leguminosas para pastos tropicais. São Paulo: Nobel/Edusp, 1983.

NASCIMENTO, J. T.; SILVA, I. de F. Avaliação quantitativa e qualitativa da fitomassa de leguminosas para uso como cobertura de solo. Ciência Rural, Santa Maria, v. 34 n. 3, p. 947-949, 2004.

PALM, C. A. et al. Organic inputs for soil fertility management in tropical agroecosystems: application of an organic resource database. Agriculture, Ecosystems and Environment, Amsterdam, v. 83, n. 1-2, p. 27-42, 2001.

PERIN, A.; GUERRA, J. G. M.; TEIXEIRA, M. G. Cobertura do solo e acumulação de nutrientes pelo amendoim forrageiro. Pesquisa Agropecuária Brasileira, Brasília, DF, v. 38, n. 7, p. 791-796, 2003.

PIRES, J. L. F.; COSTA, J. A.; THOMAS, A. L. Rendimento de grãos de soja influenciado pelo arranjo de plantas e níveis de adubação. Pesquisa Agropecuária Gaúcha, Porto Alegre, v. 4, n. 2, p. 89-92, 1998.

QI, A.; WHEELER, T. R.; KEATINGE, J. D. H. Modelling the effects of temperature on the rates of seedling emergence and leaf appearance in legume cover crops. Experimental Agriculture, Cambridge, v. 35, n. 3 , p. 327-344, 1999.

RAO, D. L. N.; GILL, H. S. Biomass production and nutrient recycling through litter from pigeonpea (Cajanus cajan L. Millsp.). Bioresource Technology, Oxford, v. 54, n. 2, p. 123-128, 1995.

RICCI, M. dos S. F. et al. Growth rate and nutritional status of an organic coffee cropping system. Scientia Agricola, Piracicaba, v. 62, n. 2, p. 138-144, 2005.

ROWDEN, R. et al. Effects of planting density on growth, light interception and yield of a photoperiod insensitive pigeon pea (Cajanus cajan). Field Crops Research, Amsterdam, v. 4, n. 3, p. 201-213, 1981.
SAKAI, E.; LEPSCH, I. F. Levantamento pedológico detalhado da Estação Experimental de Pariquera-Açu. Boletim Técnico Instituto Agronômico, Campinas, v. 83, n. 1, p. 1-56, 1984.

SALMI, G. P.; SALMI, A. P.; ABBOUD, A. C. de S. Dinâmica de decomposição e liberação de nutrientes de genótipos de guandu sob cultivo em aleias. Pesquisa Agropecuária Brasileira, Brasília, DF, v. 41, n. 4, p. 673678, 2006.

SANTOS, V. S.; CAMPELO JÚNIOR, J. H. Influência dos elementos meteorológicos na produção de adubos verdes, em diferentes épocas de semeadura. Revista Brasileira de Engenharia Ambiental, Campina Grande, v. 7, n. 1, p. 91-98, 2003.

SCHULTZE-KRAFT, R.; KELLER-GREIN, G. Crop growth and development: legumes. In: LOCH, D. S.; FERGUSON, J. E. (Eds.). Forage seed production: tropical and subtropical species. Wallingford: $\mathrm{CAB}$ International, 1999. p. 57-80.

SCOTT, W. O.; ALDRICH, S. R. Producción moderna de la soja. Buenos Aires: Hemisferio Sur, 1975.

SEIFFERT, N. F.; THIAGO, L. R. L. de S. Guandu: planta forrageira para a produção de proteína. Campo Grande: Embrapa-CNPGC, 1983. (Comunicado técnico, 21).

SILVA, J. A. A. da et al. Reciclagem e incorporação de nutrientes ao solo pelo cultivo intercalar de adubos verdes em pomar de laranjeira-'pêra'. Revista Brasileira de Fruticultura, Jaboticabal, v. 24, n. 1, p. 225-230, 2002.

SUSUKI, L. E. A. S.; ALVES, M. S. Fitomassa de plantas de cobertura em diferentes sucessões de culturas e sistemas de cultivo. Bragantia, Campinas, v. 65, n. 1, p. 121-127, 2006.

TORRES, J. L. R. et al. Decomposição e liberação de nitrogênio de resíduos culturais de plantas de cobertura em um solo de Cerrado. Revista Brasileira de Ciência do Solo, Viçosa, v. 29, n. 4, p.609-618, 2005. 